\title{
EVALUATION OF THE STRESSES INDUCED FROM ZIRCONIA TEETH ON IMPLANT RETAINED MANDIBULAR OVERDENTURE (STRAIN GAUGE ANALYSIS)
}

\author{
Ahmed M. Osama A. Shawky * and Hebatallah Tarek Mohamed ${ }^{* *}$
}

\begin{abstract}
Objective: to compare stresses induced from porcelain, zirconia and acrylic teeth on implant retained mandibular over denture.

Material and methods: For group I Porcelain teeth were retained mechanicaly in the finished denture and a stone occlussal index was made. For group II; the finished complete dentures with porcelain teeth was scanned. An impression was made of the denture with porcelain teeth then poured. The teeth were reduced to simulate teeth preparation form for crowns, the prepared abutments were scanned.The computer program integrated the initial scan of fully contoured porcelain teeth onto the tooth preparation scan for milling of the fully anatomical zirconia restorations. The zirconia teeth were attached with tooth-colored acrylic resin to the denture base. For group III, the denture with porcelain was duplicated. Tooth colored acrylic resin was applied into the mold. Universal testing machine was used to apply static load on the occlusal surface of the right first molar in vertical direction and microstrains were recorded.
\end{abstract}

Results: Two-way ANOVA test showed that the highest mean value was found in (Porcelain) while the least mean was found in (Acrylic). Post hock test showed significant difference between porcelain teeth group and other groups. It revealed statistically insignificant differences between zirconia and acrylic teeth .

Conclusions: zirconia teeth transmits less stresses than porcelain teeth and more stresses than acrylic teeth while porclain teeth transmits more stresses than both zirconia and acrylic teeth and finally the acrylic teeth showed the least amount of stressses

\footnotetext{
* Assistant Professor, Prosthodontic Department, Faculty of Dentistry Ain-Shams University

** Assistant Professor of Prosthodontics. Faculty of Dentistry. Ain Shams University
} 


\section{INTRODUCTION}

Single mandibular complete dentures is one of the challenging cases that faces the prosthodontists as it is subjected tohigh occlusal forces transmitted from the opposing natural teeth greater forces to a limitedavailable basal seat area is. ${ }^{(1)}$

A regular mandibular single denture relined with a soft relining material is one of the treatment options to absorb the forces exerted by the opposing arch. Teeth or roots in the lower arch could be retained to increase the surface area of the lower arch through the periodontal ligament of the abutment teeth and a mandibulartooth overdenture is constructed. Mandibular implant retained overdentureis considered the best treatment option for mandibular edentulous ridges. ${ }^{(2)}$

Implant supported overdenture has been used to improve edentulous patients' rehabilitation compared with conventional dentures. This can improve retention and support of the prosthesis with a better quality of life, function, chewing, nutritional status and general health. ${ }^{(3)}$

A critical aspect affecting the success or failure of an implant is the manner in which mechanical stresses are transferred from the implant to the bone. It is essential that neither implant nor bone be stressed beyond the long-term fatigue capacity. ${ }^{(4)}$

Several factors influences the amountof force transferred to the implant including the type ofthe attachment used ,the denture base material and the teeth material. ${ }^{(5)}$

Denture esthetics continues to be an important factor for patients' overall satisfaction. ${ }^{(6)}$ Successful complete dentures require a blend of science and art, in addition to the clinician's experience to achieve a pleasing appearance and function. ${ }^{(7)}$

Teeth have an important role in facial appearance, speech, and eating ability. Enhancement of facial beauty is one of the primary elective goals of patients seeking dental care. Hence the planned prosthesis should fulfill esthetic harmony, functional efficiency and structural balance with the rest of the dentofacial structures. ${ }^{(8)}$

The dentist should be aware of the evolution of dental materials and conventional laboratory techniques that enables him to offer removable restorations with natural appearance. ${ }^{(9)}$

Dentist must select denture teeth with superior physical and mechanical properties, due to their significant role in the overall esthetical outcome ${ }^{(9)}$ In addition, dental prostheses should be fabricated with a goal of reducing the amount of force to the residual ridges. Choosing appropriate denture tooth materials is one of the crucial steps in prostheses fabrication that may reduce pressure and avoid stress concentration to the supporting tissues. Artificial denture teeth composed of different materials showed different amounts and patterns of pressure distribution. ${ }^{(10)}$

Currently there are various types of commercial artificial denture teeth available, such as conventional acrylic resin teeth, porcelain teeth, improved acrylic, resin teeth including; high crosslinked acrylic resin teeth and composite resin teeth for denture fabrication. However, neither type completely accomplishes the requirements for an ideal prosthetic tooth. ${ }^{(11)}$

Acrylic resin teeth are the most widely used denture teeth; ${ }^{(12)}$ which is; highly elastic, have good chemical bond with the denture base, light in weight, better absorption of masticatory forces, high flexural impact strength therefore they are less damaging to the tissues.Moreover, they can be easily ground, recontoured and polished without compromising their properties, have a desirable natural feel, less prone to fracture, do not abrade opposing natural or artificial tooth, lack of clicking sound, reduced chipping, ease of handling and have a natural appearance. ${ }^{(13)}$ 
They have also some undesirable properties, such as low thermal conductivity, surface microporosity so they tend to become gradually discolored by pigments contained in drinks with long-term use, causing an aesthetic failure. ${ }^{(14)}$

Porcelain teeth are designed to be retained on the denture base by mechanical interlocking. The anterior teeth are made with projecting metal pins that become surrounded with the denture base resin during processing, whereas the posterior teeth are molded with diatoric spaces into which the denture base resin may flow. ${ }^{(15)}$ Ceramic artificial teeth have enjoyed some inherent advantages, such as; color superiority, color stability, they are generally considered to be more esthetically satisfactory than acrylic teeth. ${ }^{(16)}$ Ceramics are brittle and susceptible to fatigue fracture after cyclic loading. A sudden impact is more likely to chip porcelain teeth. Unlike acrylic resin which has a lower modulus of elasticity than porcelain, it will absorb much more energy before fracture. Unfortunately, porcelain teeth often cause significant wear of opposing enamel, metal, and resin tooth surfaces, especially when contacting surfaces have been roughened. Therefore, porcelain teeth should not oppose such surfaces, and if they are used, they should be polished periodically to reduce abrasive damage. ${ }^{(16)}$

The development of new dental materials and techniques has led to a greater number of treatment options that maximize the likelihood of an attractive outcome. ${ }^{(17)}$ The combination of modern materials and computer-aided design/computer-aided manufacturing (CAD/CAM) technology represents a promising approach toward optimizing the prosthodontics treatment of edentulism. Recently, CAD/CAM technology has been applied to the field of removable denture prosthodontics. This technology resulted in new restorative materials such as zirconia, glass-ceramic and heat-cured resin-based composites. These (CAD/CAM) dental ceramics are widely used in modern dentistry based on their excellent aesthetics, wear resistance, chemical stability and biocompatibility. ${ }^{(18)}$

New translucent monolithic zirconia has been developed to merge strength with improved toothcolor matching. ${ }^{(19)}$ Zirconia is one of the tooth colored materials with several advantages including; good esthetic characteristics, and excellent mechanical and biological behaviors that provide numerous indications in various clinical situations. (20) Zirconia is chemically an oxide and technologically a ceramic material, Pure, unalloyed zirconia is polymorphic and allotropic at ambient pressure, presenting three crystallographic shapes at different temperatures: cubic (c) (from $2680^{\circ} \mathrm{C}$, the melting point, to $2370^{\circ} \mathrm{C}$ ), tetragonal (t) (from $2370^{\circ} \mathrm{C}$ to $1170^{\circ} \mathrm{C}$ ), monoclinic (m) (from $1170^{\circ} \mathrm{C}$ to room temperature).When, upon cooling, the spontaneous transformation from the $(\mathrm{t})$ phase to the more stable (m) phase occurs, a simultaneous, noticeable volume increase of the crystals (4-5\%) ensues creating high compressive stresses in the material. (21) $^{2}$

Monolithic 3 mol\% yttria-doped tetragonal zirconia polycrystal (3Y-TZP) is the most widely used zirconia material for dental applications; which has a high fracture toughness ranging between 5 and $10 \mathrm{MPa}$ and flexural strength ranging between 900 and $1400 \mathrm{MPa}$. These physical properties are the highest of all dental ceramics presently available.(22) and elastic modulus (200-210 GPa).

Zirconia has better mechanical properties than other ceramics, including alumina, glass ceramics, and lithium disilicate. Zirconia is used to manufacture frameworks due to better mechanical properties; higher wear resistance, more resistance to fracture than other brittle dental ceramics ${ }^{(23)}$ and showed low wear of the enamel antagonist as well. ${ }^{(22)}$

Technological improvements in design and manufacture led to the fabrication of zirconia teeth for the removable dental prostheses. This material replaces the metal casting process with esthetically 
pleasing outcome that eliminates problems caused by the gray effect of metal substrates. ${ }^{(24)}$

Monolithic zirconia is emerging as a promising option to be used as a denture tooth material. However, the material properties should be confirmed before clinical use, after which the material can serve as one of the clinician's evidencebased material options. ${ }^{(25)}$

\section{MATERIALS AND METHODS}

In this in vitro study, patient's completely edentulous mandibular arch stone model was used as a template for the test model construction. An impression of the model was made and poured with molten base plate wax using a mechanical vibrator.

After hardening, the cast in wax was removed and processed into heat polymerizing acrylic resin model forming an edentulous mandibular test model.

On the patient's stone model three complete dentures were constructed and divided into three groups; group I having complete denture with porcelain teeth, group II having complete denture with zirconia teeth while group III having complete denture with acrylic teeth.

For all the groups shellac base plates trial denture bases were fabricated.

In group I; porcelain teeth* size 24 was used where the anterior teeth were retained by metal pins in the denture base, while the posterior teeth have diatoric spaces for retention in the denture base. Setting up of teeth was done following the lingualized concept of occlusion. The teeth were placed with the central groove of posterior teeth centralized over crest of the ridge and the height of occlusal plane was set from the tip of canine to the bottom of the upper third of retromolar pad. The waxed up overdenture was then processed into heat polymerizing acrylic resin. Fig. (1), the denture was finished and polished and a stone occlussal index was made .

For group II; the finished complete over dentures with porcelain teeth was scanned by CAD/ CAM system** extraoral scanner to record the full contours and occlusal anatomy of the porcelain teeth. Fig. (2)

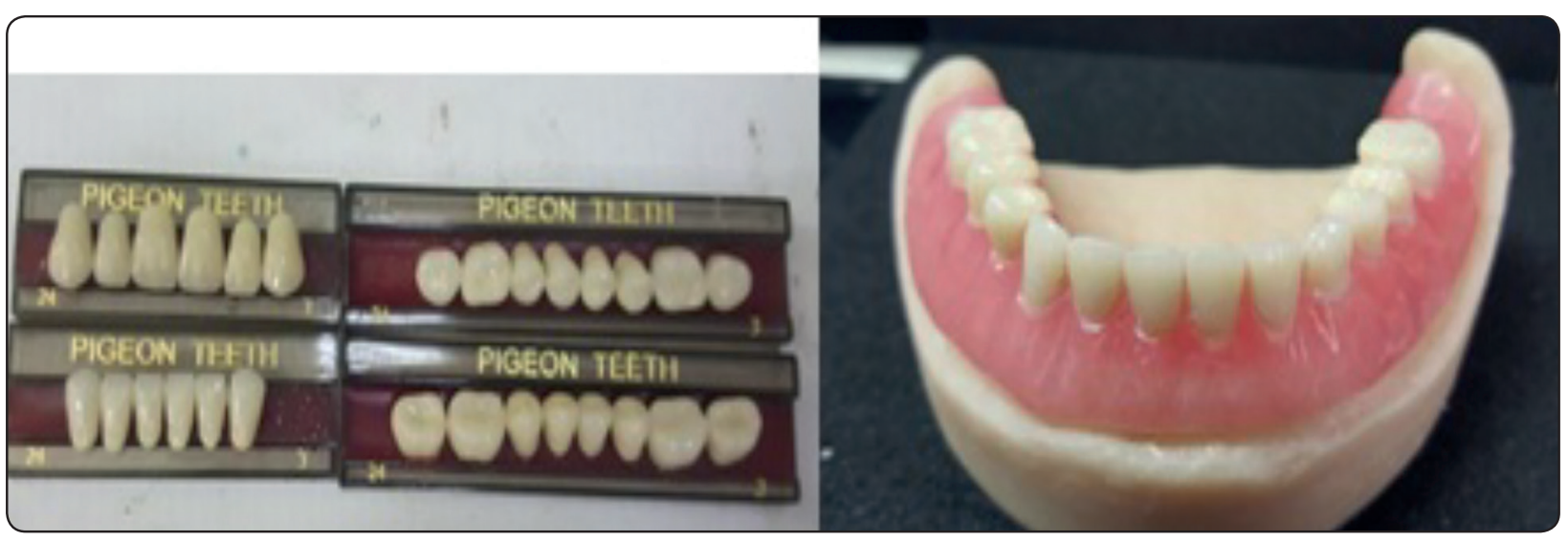

Fig. (1): Complete denture with porcelain denture teeth.

\footnotetext{
* Porcelain teeth, Shanghai Pigeon Dental Mfg. Co., Ltd.

** AMANNGIRRBACH CAD/CAM system,
} 


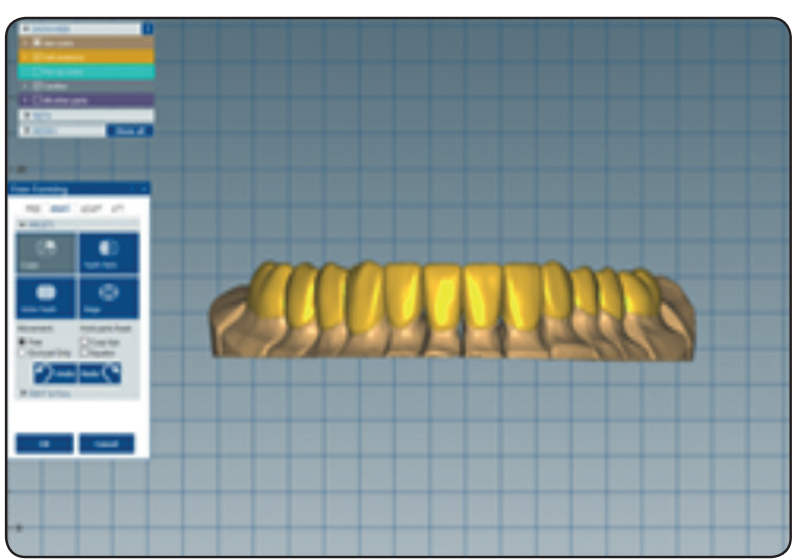

Fig. (2): A scan of the porcelain teeth.

An impression was made of the denture with porcelain teeth, using silicone rubber base impression material. The impression was poured in hard stone. After ditching the stone cast, the teeth were reduced to simulate teeth preparation form for crowns using a tapered with round end stone 0.5 $\mathrm{mm}$ in diameter guided by a dental surveyor* with a straight handpiece. Fig(3)

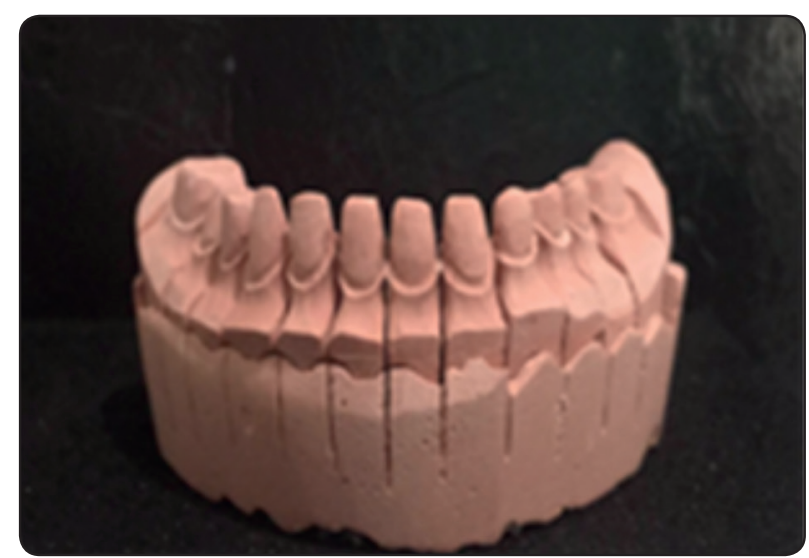

Fig. (3): Prepared abutments with $0.5 \mathrm{~mm}$ finish line.

Then, the prepared abutments were scanned to serve as prepared dies for the design of zirconia teeth. The computer program integrated the initial scan of fully contoured porcelain teeth onto the tooth preparation scan to enable the designing,

\footnotetext{
* NOUVAG AG CH-9403 Goldach

** Ceramillzolidfx, Austria.

*** DD Basic Shade-Set, Dental Direkt GmbH, Germany

**** Cerabien ZR FC Paste stain, Kuraray Noritake, America
}

processing, and milling of the fully anatomical zirconia restorations.Fig (4)

After milling of the monolithic zirconia teeth ${ }^{* *}$ of $0.5 \mathrm{~mm}$ thickness and prior to sintering, perforations were made in the cervical areas of the teeth for their retention within the denture base. Fig (5). The teeth were then stained using zirconia coloring liquids ${ }^{* * *}$, sintered, further stained, and glazed using stain paste $^{* * * * *}$.

The zirconia teeth were repositioned and waxed on the shellac trial denture base guided by a stone

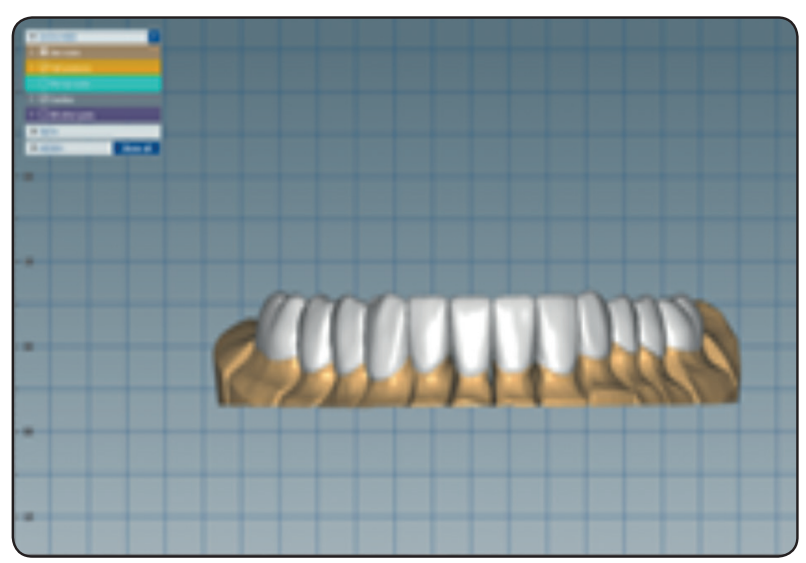

Fig. (4): Designing the fully anatomical zirconia restorations

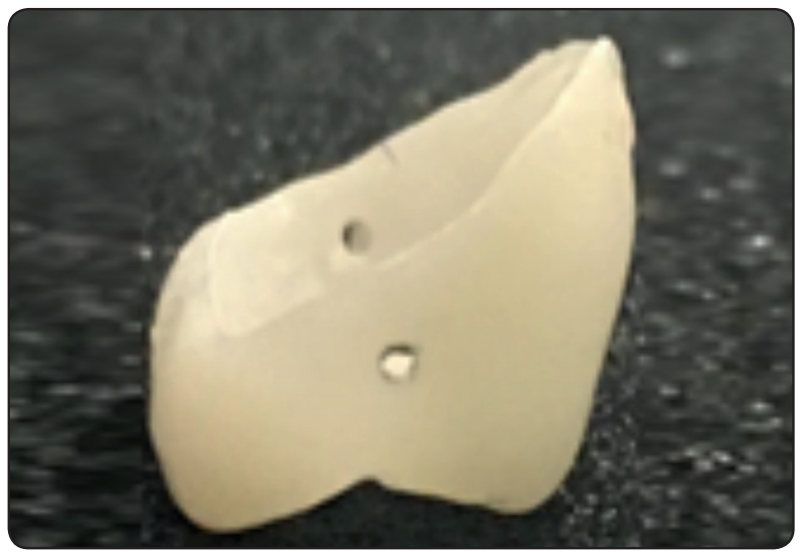

Fig. (5): Perforations in the cervical areas of the teeth for retention of the crowns within the denture base. 
occlusal index fabricated on the complete denture with porcelain teeth. After flasking the denture and wax elimination, the zirconia teeth were filled with tooth-colored cold cured acrylic resin till the gingival margin of the teeth. The flask was closed and left until complete polymerization. Heat polymerizing acrylic resin was then mixed, and packed into the flask, and processed in the usual manner, then finished and polished followed by packing heat-polymerizing acrylic resin material for denture base, after processing the denture was finished and polished. Fig(6)

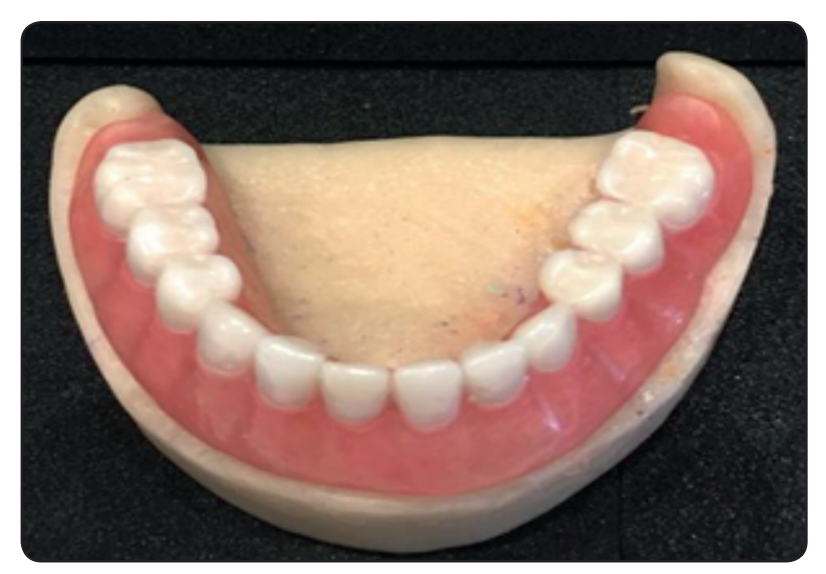

Fig. (6): Mandibular complete denture with monolithic zirconia teeth.

For group III , the denture with porcelain was duplicated where the denture was flasked in the usual manner. The denture was then removed from the flask. Tooth colored autopolymerizing acrylic resin* was mixed, and applied into the mold which was filled till the gingival margin of the teeth. The flask was closed and left until complete polymerization. Heat polymerizing acrylic resin** was then mixed, and packed into the flask, and processed in the usual manner, then finished and polished.

In each model, six implants $3.5 \mathrm{~mm}$ in diameter and $13 \mathrm{~mm}$ in length were placed in the lateral incisor region, first premolar region and first molar region of each side, a milling machine was used to drill the implant sites then the implants were fixed with autopolymerizing acrylic resin. For all the groups the housing with the oring was placed over the ball abutment and recesses were prepared in the fitting surface of the denture using a round bur opposite to the attachment, so that the denture fits passively on the cast. The attachment system were picked up into the mucosal surfaces of the denture using an autopolymerizing acrylic resin.

The acrylic casts were boxed in boxing wax and painted with separating medium, and dental stone was poured over the boxed model on a mechanical vibrator, after setting, the index was separated from the cast.

A layer of $2 \mathrm{~mm}$ uniform thickness was removed from the surface of the denture bearing area. This was performed using a $2 \mathrm{~mm}$ diameter round bur to prepare depth cuts in the denture bearing area, then uniform reduction was performed using acrylic bur. The strain gauges*** used in this study were supplied with fully encapsulated grid and attached wires. The wire used for the strain gauges was insulated by a packing material. A fissure bur was used to prepare the model to receive the strain gauge $1 \mathrm{~mm}$ distal to each implant.

At these sites the acrylic alveolar ridge distal to each implant was reduced and thinned parallel to the implant's long axis, to form a box like chamber of acrylic resin $1 \mathrm{~mm}$ in thickness for the strain gauges to be embedded in these chambers.

In each model six strain gauges (KFG-1-120C1-11L1M2R, with gauge factor $2.08 \pm 1.0 \%$, guage length $1 \mathrm{~mm}$, guage resistance $120.4 \pm 0.4 \Omega$, adaptor thermal expansion $11.7 \mathrm{PPM} /{ }^{\circ} \mathrm{C}$, and temperature coefficient of gauge factor $+0.008^{\circ} \mathrm{C}$ ) were installed each $1 \mathrm{~mm}$ distal to each implant.

\footnotetext{
* Acrostone dental, Egypt

** Heat polymerizing acrylic resin, Acrostone dental, Egypt

*** Kyowa strain gauge,Kyowa electronic instruments Co.,LTD.Japan
} 
Wires of the strain gauges were oriented vertically in the created chambers and fixed in position using an adhesive recommended by the manufacturer*. The reduced denture bearing area was painted with rubber base adhesive and left to dry for 5 minutes.

A medium bodied addition silicon rubber base impression material with nearly the same viscoelasticity of the oral mucosa was injected over the reduced residual ridge. The stone index was painted by separating medium and repositioned to its previous position on the acrylic model till complete setting of the impression material.

Universal testing machine** was used to apply standardized static load with a magnitude of 100 $\mathrm{N}$ were applied to the experimental overdentures. Loading was performed on the occlusal surface of the right first molar in oblique and vertical unilateral and bilateral direction. Microstrains were recorded at each site of the strain gauges with enough time elapsed between each testing.

The values of the recordings from the strain gauges (strain), were used as an indicator of the stress generated in the peri-implant bone. Five minutes were left to elapse between successive measurements. All the gauges were zero balanced before taking the next reading

\section{RESULTS}

Statistical analysis was performed using Microsoft office 2010(Excel) and statistical package for social science (SPSS) version 20.Microstrain data was presented as mean and standard deviation values.

The mean and standard deviation values were calculated for each group in each test. Data were explored for normality using Kolmogorov-Smirnov and Shapiro-Wilk tests, data showed parametric (normal) distribution.

Repeated measure ANOVA was used to compare between more than two groups in related samples. Paired sample t-test was used to compare between two groups in related samples. Independent sample t-test was used to compare between two groups in non-related samples.

Two-way ANOVA test followed by Tukey`spost hoc test was used to test the interactions between different variables.

The significance level was set at $\mathrm{P} \leq 0.05$. Statistical analysis was performed with $I B M ®$ SPSS $®$ Statistics Version 20 for Windows. Table (I): represent the mean and standard deviation (SD) values of strain of different teeth materials.

TABLE (I): The mean and standard deviation (SD) values of strain of different teeth materials.

\begin{tabular}{|c|c|c|c|c|c|c|c|}
\hline \multirow{2}{*}{ Variables } & \multicolumn{2}{|c|}{ Oblique } & \multicolumn{2}{c|}{ Vertical unilateral } & \multicolumn{2}{c|}{ Vertical bilateral } & \multirow{2}{*}{ p-value } \\
\cline { 2 - 8 } & Mean & SD & Mean & SD & Mean & SD & \\
\hline Porcelain & $64.63^{\mathrm{a}}$ & 4.7864 & $47.25^{\mathrm{a}}$ & 3.05348 & $173.13^{\mathrm{a}}$ & 4.0819 & $<\mathbf{0 . 0 0 1 *}$ \\
\hline Zirconia & $24.38^{\mathrm{b}}$ & 2.26126 & $21.75^{\mathrm{b}}$ & 1.01324 & $72.00^{\mathrm{b}}$ & 5.4904 & $<\mathbf{0 . 0 0 1 *}$ \\
\hline Acrylic & $10.45^{\mathrm{b}}$ & 1.6675 & $11.32^{\mathrm{b}}$ & 1.2383 & $21.39^{\mathrm{b}}$ & 2.5634 & $<\mathbf{0 . 0 0 1 *}$ \\
\hline $\boldsymbol{p}$-value & \multicolumn{3}{|c|}{$<\mathbf{0 . 0 0 1} *$} & \multicolumn{2}{|c|}{$<\mathbf{0 . 0 0 1}^{*}$} & \\
\hline
\end{tabular}

Different superscript letters indicate a statistically significant difference

\footnotetext{
*Cyanoacrylate cement, Germany

**LLOYD instruments, universal testing machine, UK
} 
From this table, Two-way ANOVA test showed that the highest mean value was found in (Porcelain) in both vertical and oblique directions, while the least mean value was found in (Acrylic). Statistical analysis of the data revealed a significant difference between different groups where $(\mathrm{p}<0.001)$. Post hock test showed significant difference between porcelain teeth group and other groups. On the other hand, it revealed statistically insignificant differences between zirconia and acrylic teeth group.

\section{DISCUSSION}

Completely edentulous patients are frequently suffering from the inadequate retention and stability of their mandibular dentures. Most of these patients preferred the implant overdenture as an economic, esthetically acceptable and applicable line of treatment ${ }^{-(26)}$

Implant supported overdenture success depend on stresses distribution and minimizing the forces transmitted to the implants as well as peri-implant bone loss. ${ }^{(27)}$

Implants overloading is the main factor responsible for bone resorption. Furthermore, the intensity and amplitude of bone resorption is determined by the forces transmission and distribution. ${ }^{(28)}$

This in-vitro study was conducted to evaluate and compare the stresses transmitted by different denture teeth materials including acrylic denture teeth ,porcelain denture teeth and CAD/CAM milled zirconia teeth on implant retained mandibular overdenture using stain gauge analysis.

This study was carried out in vitro because laboratory studies allow for better control over variables and yield more accurate results. ${ }^{(29)}$ Strain gauge technology was used in this study because it is sensitive, stable, accurate and reproducible on the selected sites. ${ }^{(30)}$ Mandibular ridge exhibits a decrease in the size of the denture bearing area which may be associated with problems in denture stability, support and retention. So the study was carried out on lower model. ${ }^{(31)}$

Denture base fabrication in the study was controlled to be the same in every specimen using shellac denture base material to standardize the denture base thickness in all specimens, thus, the results were compared only with respect to the different artificial denture teeth materials. ${ }^{(32)}$

For standardization the occlusal form for all groups; complete denture with porcelain teeth were scanned to produce zirconia teeth and duplicated to form acrylic teeth with similar anatomical form. Therefore, the size and shape of denture teeth used were equalized, and the results compared only the different tooth materials. ${ }^{(25)}$

The recommended thickness for translucent zirconia based on in vitro studies is $0.5 \mathrm{~mm}$ for occlusal and axial surfaces. A light chamfer or round shoulder finish line is recommended with $0.5 \mathrm{~mm}$ thickness. ${ }^{(33)}$ After milling and prior to sintering the crowns, perforations were made in the cervical areas of the teeth for retention of the crowns within the denture base. ${ }^{(25)}$

Strain gauge technology was used due to its accuracy, stability, sensitivity and reproducibility on the selected sites. It depends on the idea of covering the change in resistance in an electric wire into strain measurement. The used wire was insulated by a packing material to protect it from humidity, which was reported to be essential for obtaining reliable recordings. ${ }^{(34)}$

LLOYD digital loading device was used to deliver ascending load in this study due its ease of use. Moreover, it offers rapid data, high accuracy position measurement, rapid data acquisition and full personal computer integration. ${ }^{(35)}$

Denture teeth made of different materials showed varying amounts and patterns of pressure distribution. ${ }^{(10)}$ 
The results obtained from this study showed thatin different loading situations, different types of denture teeth materials transmit different stresses to the implant supporting structures where the highest mean strain value was found in the group of porcelain teeth and the lowest mean strain value was found in the group of acrylic teeth.

Teeth materials with high modulus of elasticity showing less deformation with more damping effect while materials with low moduli of elasticity showing higher deformation and less damping effects to the supporting structures. These observations are consistent with Hooke's law: the higher the modulus of elasticity, the lower the deformation, and the more likely the forces transferred through the materials. ${ }^{(36,37)}$

The viscoelastic properties of porcelain and acrylic resin teeth was measured and demonstrated that the absorbing energy of acrylic resin teeth is approximately $20 \%$ higher than that of porcelain teeth and concluded that acrylic resin teeth should be selected when higher shock-absorbing ability is required. ${ }^{(38)}$

It was suggested that the resin teeth had greater toughness and higher shock-absorbing ability than the more brittle porcelain teeth. ${ }^{(39)}$ Researches proved that porcelain teeth transmit a greater proportion of the masticatory forces to the underlying mucosa and bone in comparison to the acrylic teeth, causing localized stress concentration underneath the denture base. ${ }^{(10)}$

Zirconia teeth showed less forces transmitted than porclain teeth with significant difference between the two groups and it showed higher forces transmitted to the implant supporting structures compared to acrylic teeth but the difference between the these two groups was insignificant.

Zirconia has been used due to its biocompatible properties, offering superior strength, toughness and reliability over other ceramic materials due to the transformation toughening mechanisms of its microstructure. ${ }^{(40)}$
The mechanical properties of zirconia are the highest ever for any dental ceramic. ${ }^{(41)}$ Monolithic zirconia crowns also provide a higher reliability and better capability to sustain loading..$^{(42)}$ monolithic zirconia should be used due to its higher fracture resistance at minimum thicknesses compared to veneered counterparts and other monolithic ceramics. ${ }^{(43,44)}$

It is also believed that using zirconia crowns with small thickness $(0.5 \mathrm{~mm})$ in the current study led to a decrease in the stress values transmitted to the underlying model unlike the body porcelain teeth. As the strongest and toughest of all dental ceramics, these characteristics enable the manufacturing of monolithic zirconia crowns with thin thickness. ${ }^{(43,45,46,47)}$

Thus, it can be speculated from the results of this study that using monolithic zirconia crowns of thin thickness $(0.5 \mathrm{~mm})$ filled with acrylic resin as denture teeth materials brought together the shock absorption of acrylic resin and dissipation of stresses transmitted to the underlying structures with hardness and wear resistance of zirconia with high mechanical properties. ${ }^{(48)}$

\section{CONCLUSIONS}

Within the limitation of this study it can be concluded that porcelain teeth cause more strain followed by zirconia and the least from acrylic teeth in case of implant supported mandibular overdenture.

\section{REFERENCES}

1. Laxman S. and Richa S.: Single complete denture inmandibular arch opposing natural dentition - a casereport. NUJHS. 3; 2249, 2013.

2. MajSatyendra K., Col Kumar D., Lt Col Legha V. and Lt Col Kumar A.: Specially designed tooth supported mandibular overdenture with enhanced retention. MJAF IndiaXXX; 1, 2015.

3. Zarb G.; Bolender C. and CorlssonG. :Boucher's prosthetic treatment for edentulous patients. C. V. Mosby Co, Saint Louis, p.80, 1997. 
4. Meijer HJA, Kuiper JH, Starmans FJM and Bosman FJM.: Stress distribution around dental implants: influence of superstructure, length of implant and height of mandible. J Prosthet Dent. 1992;68:96-102.

5. Heckmann SM, Winter W.: Overdenture attachment selection and the loading of implant and denture-bearing area. Part 2: A methodical study using five types of attachment Clin. Oral Impl.Res.12; 640-647, 2001.

6. Michael McCunniff, Wei Liu, Deborah Dawson and Leonardo Marchini.Patients' esthetic expectations and satisfaction with complete dentures.JProsthet Dent. 2017; 118(2):159-165.

7. Gomes VL, Gonçalves LC, do Prado CJ, Junior IL, de Lima Lucas B. Correlation between facial measurements and the mesiodistal width of the maxillary anterior teeth. J EsthetRestor Dent. 2006;18(4):196-205

8. Patras M1, Kourtis S, Sykaras N. Creating natural-looking removable prostheses: combining art and science to imitate nature. J EsthetRestor Dent. 2012;24(3):160-8.

9. Winkler S. Essentials of complete denture Prosthodontics. 2. Delhi, ATIBS, 2012. p. 222.

10. Phunthikaphadr T, Takahashi H, Arksornnukit M. Pressure transmission and distribution under impact load using artificial denture teeth made of different materials. J Prosthet Dent. 2009;102(5):319-27.

11. Zarb GA, Bolender CL. Eckert SE, Jacob RF, Fenton AH, Merickske-stern RM. Prosthodontic treatment for edentulous patients: Complete denture and Implant-supported prosthesis. 12th ed. St. Louis: Mosby; 2004. p. 195-8.

12. Freire TS, Aguilar FG, Garcia LF, Pires-de-Souza FC. Colour stability of denture teeth submitted to different cleaning protocols and acceleratedartificial aging. Eur J ProsthodontRestor Dent. 2014;22(1):24-7.

13. Marra J, Souza RF, Barbosa DB, Pero AC, Compagnoni MA. Evaluation of the bond strength of denture base resins to acrylic resin teeth: effect of thermocycling. J Prosthodont. 2009;18(5):438-43.

14. Gregorius WC, Kattadiyil MT, Goodacre CJ, Roggenkamp CL, Powers JM, Paravina RD. Effects of ageing and staining on color of acrylic resin denture teeth. J Dent. 2012;40(2):47-54.

15. Kenneth J. Anusavice, ChiayiShen and H. Ralph Rawls. Phillips'.Science of Dental Materials. 12th edn., St. Louis, Elsevier; p.463.
16. Temel KOKSAL and IdilDIKBAS.Color Stability of Different Denture Teeth Materials against Various Staining Agents. Dent Mater. 2008; 27(1):139-144.

17. S. Nasrin, N. Katsube, R.R. Seghi.Survival Predictions of Ceramic Crowns Using Statistical Fracture Mechanics. J Dent Res. 2017; 96 (5): 509-515.

18. Avinash S. Bidra, Thomas D. Taylor and John R. Agar. Computer-aided technology for fabricating complete dentures: Systematic review of historical background, current status, and future perspectives. J Prosthet Dent 2013;109(6):361-366.

19. Ghodsi S, Jafarian Z. A Review on Translucent Zirconia. Eur J ProsthodontRestor Dent.2018;26(2):62-74.

20. Zhang Y, Lawn BR. Novel zirconia materials in dentistry. J Dent Res. 2018;97(2):140-147.

21. Guazzato, M, Albakry, M, Ringer, SP, Swain, MV. Strength, fracture toughness and microstructure of a selection of all-ceramic materials: Part II. zirconia-based dental ceramics. Dent Mater. 2004; 20(5):449-456.

22. Zhang, F, Inokoshi, M, Batuk, M, Hadermann, J, Naert, I, VanMeerbeek, B, Vleugels, J..Strength, toughness and aging stability of highly-translucent Y-TZP ceramics for dental restorations. Dent Mater. 2016; 32(12):e327-e337.

23. ParissaNassaryZadeh, Nina Lümkemann, Beatrice Sener, MarlisEichberger, and BognaStawarczyk. Flexural strength, fracture toughness and translucency of cubic/tetragonal zirconia materials. J Prosthet Dent 2018; 120(6): 948-954

24. Sulaiman TA, Abdulmajeed AA, Donovan TE.Optical properties and light irradiance of monolithic zirconia at variable thicknesses. Dent Mater 2015;31(10):1180-1187.

25. Livaditis JM1, Livaditis GJ. The use of custom-milled zirconia teeth to address tooth abrasion in complete dentures: a clinical report. J Prosthodont. 2013;22(3):208-13.

26. MostafaOmran, AlaaAbdelhamid, AmrElkarargy, Mahmoud Sallom. Mini-implant overdenture versus conventional implant overdenture (A radiographic and clinical assessments). J Am Sci 9(9):89-97, 2013.

27. Porter JA and Von Fraunhofer JA: Success or failure of dental implants? A literature review with treatment considerations. J. Dent. Res. 53:423-433, 2005.

28. Fanuscu MI, Caputo AA: Influence of attachment systems on load transfer of an implant-assisted maxillary overdenture. J Prosthodont. 13:214-220, 2004. 
29. Doundoulakis J., Eckert S., Lindquist C.: The implant supported overdenture as an alternative to the complete mandibular denture. J Am Dent Assoc 134: 155-160, 2003.

30. Duyck J, Van Oosterwyck H: Three-dimentional force measurments on oral implants: a methodological study. J Oral Rehabil. 27:744-53, 2000.

31. Singh R. D., Ramashanker, Chand P.: Management of atrophic mandibular ridge with mini dental implant system. National Journal of Maxillofacial Surgery I Vol 1 । Issue 2 | Jul-Dec 2010.

32. Alan H., Some physical and mechanical properties of shellac dental baseplate material. J. Oral Rehab.1995; 22(7):509-13.

33. Caroline Sachsa, Julian Groessera, Markus Stadelmannb, Josef Schweigera, Kurt Erdelta, Florian Beuer. Full-arch prostheses from translucent zirconia: Accuracy of fit. Dent Mater. 2014;30(8):817-23

34. Ragab D. Extracoronal Resilient Attachement Versus Ball Attachment for Mini Dental Implants Retained Mandibular Overdenture (In Vitro Study). D.D.S.,thesis, Ain shams University, 2014.

35. Hegazy SA, Elshahawi IM, Elmotayam H. Stresses induced by mesially and distally placed implants to retain a mandibular distal-extension removable partial overdenture: a comparative study. Int J Oral Maxillofac Implants. 2013;28(2):403-7.

36. Phunthikaphadr T, Takahashi H, Arksornnukit M. Pressure transmission and distribution under impact load using artificial denture teeth made of different materials. J Prosthet Dent. 2009;102(5):319-27.

37. Rosentritt M, Schneider-Feyrer S, Behr M, Preis V. In Vitro Shock Absorption Tests on Implant-Supported Crowns: Influence of Crown Materials and Luting Agents. Int J Oral Maxillofac Implants. 2018;33(1):116-122.
38. Shimoyama S, Uchida T, Nagao M, Odagiri K, Shirasaki Y, Tateishi T. Mechanical properties of artificial teeth. Bull Tokyo Med Dent Univ 1993;40(1):13-16.

39. Shimoyama K. Dynamic viscoelastic properties of models composed of posterior denture teeth and denture base resin. J Med Dent Sci 1998; 45(2): 117-121.

40. Ghodsi S, Jafarian Z. A Review on Translucent Zirconia. Eur J ProsthodontRestor Dent.2018;26(2):62-74.

41. Denry, I, Kelly, JR. State of the art of zirconia for dental applications. Dent Mater. 2008;24(3):299-307.

42. Zhang Y, Mai Z, Barani A, Bush M, Lawn B. Fractureresistant monolithic dental crowns. Dent Mater. 2016; 32(3):442-9.

43. Ji-Hee Park, Sangwon Park, Kwangmin Lee, Kwi-Dug Yun, and Hyun-Pil Lim. Antagonist wear of three CAD/ CAM anatomic contour zirconia ceramics. J Prosthet Dent 2014;111(1):20-29

44. Bijjargi S, Chowdhary R. Stress dissipation in the bone through various crown materials of dental implant a 2-D finite element analysis. J InvestigClin Dent 2013; 4(3):172-7.

45. RaminMosharraf, FarzadZiaei, and MahsaAbbasi. Effect of Denture Tooth Material on Load Transmission Under Denture Bases. J Dent (Tehran). 2018; 15(5): 325-331.

46. Magne P, Silva M, Oderich E, Boff LL, Enciso R. Damping behavior of implant-supported restorations. Clin Oral ImplanRes. 2013;24 (2):143-8.

47. Özlem Malkondu, Neslihan Tinastepe, Ender Akan \& Ender Kazazoğlu. An overview of monolithic zirconia in dentistry. J Biotech.\& Biotech. Equip. 2016;30(4):1-9.

48. Kawano F, Ohguri T, Ichikawa T, Mizuno I, Hasegawa A. Shock absorbability and hardness of commercially available denture teeth. Int J Prosthodont 2002;15(3):243-7. 